\title{
Balanced scorecard: estudo de caso aplicado para o desenvolvimento e crescimento estratégico de uma microempresa
}

Este estudo tem como proposta a aplicação de uma ferramenta auxiliar de gestão estratégica o Balanced Scorecard em uma microempresa de treinamento no setor tributário para definir e avaliar o desempenho de estratégias em quatro vertentes, a financeira, os clientes, os processos internos da organização e o nível de conhecimento ou aprendizagem organizacional. Em relação à abordagem do problema, este estudo classifica-se como qualitativo. A interpretação qualitativa dos fatos contribui com o processo de mudança referente à análise de desempenho no decorrer das etapas de desenvolvimento estratégico e de implementação do Balanced Scorecard da empresa. Como resultado chegou-se ao painel estratégico, onde se mapeou os objetivos estratégicos e seus respectivos indicadores, destacamos que muitas implantações de algumas propostas serão futuras, pelo fato de ser uma empresa em inícios de suas atividades, destacando as metas a serem alcançadas e qual a iniciativa necessária para isto, através do levantamento das missões, visão e valores. Foram encontradas várias dificuldades para implantação das ideias propostas, pelo tamanho da empresa e principalmente pelo fato da concentração de informações. A ferramenta utilizada foi aprovada pelo empresário, mostrando-se uma importante ferramenta para avaliação do desempenho no setor em estudo capaz de fornecer informações importantes para decisões futuras da empresa e principalmente uma forma de manter a empresa em um mercado competitivo e com várias turbulências econômicas e financeiras.

Palavras-chave: Balanced Scorecard; Desenvolvimento e Crescimento Estratégico; Microempresa.

\section{Balanced scorecard: case study applied for development and strategic growth of a micro-company}

\begin{abstract}
This study proposes the application of an auxiliary tool for strategic management, the Balanced Scorecard in a microenterprise of training in the tax sector to define and evaluate the performance of strategies in four aspects, the financial, the clients, the internal processes of the organization and the level of knowledge or organizational learning. Regarding the approach to the problem, this study is classified as qualitative. The qualitative interpretation of the facts contributes to the process of change regarding performance analysis during the company's strategic development and Balanced Scorecard implementation stages. As a result, we arrived at the strategic panel, which mapped the strategic objectives and their respective indicators. We highlight that many implementations of some proposals will be future, due to the fact that it is a company in the beginning of its activities, highlighting the goals to be achieved and what the initiative needed for this by surveying the missions, vision and values. Several difficulties were encountered for the implementation of the proposed ideas, due to the size of the company and mainly due to the concentration of information. The tool used was approved by the entrepreneur, proving to be an important tool for performance evaluation in the sector under study capable of providing important information for future decisions of the company and especially a way to keep the company in a competitive market and with various economic and turbulence.
\end{abstract}

Keywords: Balanced Scorecard; Development and Strategic Growth; Micro enterprise.

Topic: Planejamento, Estratégia e Competitividade

Reviewed anonymously in the process of blind peer.
Received: 11/06/2020

Approved: 29/07/2020
Ana Paula Haskel (iD)

Universidade Federal de Santa Catarina, Brasil http://lattes.cnpq.br/1285735936056598

http://orcid.org/0000-0002-2517-6147

anaphaskel@gmail.com

Sérgio Murilo Petri

Universidade Federal de Santa Catarina, Brasil

http://lattes.cnpq.br/2579064028361832

http://orcid.org/0000-0002-1031-7939

sergio.petri@ufsc.br

\section{Referencing this:}

HASKEL, A. P.; PETRI, S. M.. Balanced scorecard: estudo de caso aplicado para o desenvolvimento e crescimento estratégico de uma microempresa. Revista Brasileira de Administração Científica, v.11, n.3, p.100-112, 2020. DOI: http://doi.org/10.6008/CBPC2179684X.2020.003.0007 


\section{INTRODUÇÃO}

Os dados sobre a longevidade de micro e pequenas empresas (MPEs) no Brasil revelam que, de cada 100 que iniciam sua operação no Brasil, 73 permanecem em atividade após os primeiros dois anos de existência, esses são dados do Serviço Brasileiro de Apoio às Micro e Pequenas Empresas (Sebrae), uma entidade privada brasileira de serviço social, sem fins lucrativos de Apoio às Micro e Pequenas Empresas. Segundo, também, dados do Departamento Nacional de Registro Comercial (DNRC), ligado ao Ministério do Desenvolvimento, Indústria, e Comércio Exterior (MDIC), são constituídas no Brasil em torno de 440 mil novas empresas por ano, mas dessas cerca de 80 mil fecham.

O Sebrae descreve o que é fundamental para sobrevivência de uma empresa, destacando, a saber, a necessidade de planejamento, o respeito à capacidade financeira da empresa, a observação da concorrência, o controle do estoque, o investimento em formação empresarial e fidelidade aos seus valores e ao seu negócio. Nesse sentido, avaliação de desempenho organizacional é atualmente um tema de grande interesse profissional e acadêmico, pois gera vantagens competitivas para o meio privado e ainda garante a sustentabilidade e consequentemente as perspectivas futuras.

Um autor buscou quais abordagens sobre o tema são as mais frequentes na literatura, encontrando 34 abordagens que buscam avaliar o desempenho de diversas maneiras. Dentre essas, Neely (2005) destaca algumas como a pirâmide de desempenho e hierarquias, a pirâmide SMART, o Scorecard do ativo intangível, o prisma de desempenho, a matriz de avaliação de desempenho, o quadro do resultado determinante e o Balanced Scorecard. Com isso, o Balanced Scorecard (BSC) tem o propósito estratégico de posicionar a empresa no mercado funcionando como ferramenta auxiliar ao planejamento dela. Mooraj et al. (1999) apuraram que o uso do Balanced Scorecard (BSC) é um "bem necessário", pois ajuda a tomada de decisão com informações equilibradas e concisas. Ao longo dos anos, o BSC evoluiu para uma ferramenta de gestão estratégica e por isso passou a receber ainda mais atenção dos profissionais e acadêmicos.

Além disso, em contexto competitivo e de economia frágil as empresas brasileiras têm passado por várias dificuldades para se manter no mercado, vários índices de mortalidade delas são estudados e discutidos e as microempresas não estão fora deste cenário. Devido a isso, este estudo tem como proposta a aplicação dessa ferramenta auxiliar de gestão estratégica, que é o Balanced Scorecard, em uma microempresa de treinamento no setor tributário para que possa, inicialmente, definir e avaliar o desempenho de estratégias em quatro vertentes que são a financeira, os clientes, os processos internos da organização e o nível de conhecimento ou aprendizagem organizacional.

A partir da literatura de Kaplan e Norton, só é possível gerenciar aquilo que medimos, com isso este estudo justifica-se por encontrar-se em uma área não muito explorada, que é a aplicação da ferramenta BSC para as microempresas. De acordo com isso, poderemos encontrar formas palpáveis para o gerenciamento dessas empresas que sofrem de forma considerável pela falta de informação e aplicação das estratégias de comprovado sucesso. Assim, O estudo traz uma contribuição prática ao propor essa ferramenta de gerenciamento de informações aplicada à empresa de porte menor, o que não é usualmente feito e 
estudado. Dessa forma propõe-se a estrutura da presente pesquisa que é composta da seguinte forma: a seção a seguir discute o referencial teórico, seguido da que expõe os aspectos metodológicos. Na sequência são apresentados os resultados e suas análises, seguidos pelas considerações finais.

\section{REVISÃO TEÓRICA}

\section{Balanced Scorecard}

O Balanced Scorecard, conhecido também pelas iniciais BSC, trata-se de uma ferramenta de apoio à gestão estratégica, refere-se e não deve ser utilizada como uma finalidade, e sim como um meio para alcançar alguns objetivos dentro de uma empresa. Em termos históricos, sabe-se que a ferramenta BSC foi proposta pela primeira vez em 1992 no artigo The balancedscorecard - measuresthat drive performance, publicado na Harvard Business Review por Robert Kaplan e David Norton. No primeiro momento os autores concluíram que os demonstrativos contábeis, e as informações que eles traziam, não eram suficientes para atender aos interesses e necessidades da administração, responsável pela tomada de decisões. Como os sistemas de avaliação, até a época haviam nascido na área contábil e financeira, eram focados no controle, enquanto deveriam focar também com as estratégias e a visão da empresa (KAPLAN et al., 2004).

Este instrumento serviria para as entidades executarem os seus planejamentos estratégicos, observando o desenvolvimento das atividades propostas pela empresa. Kaplan e Norton dividiram então o BSC em quatro perspectivas: financeira, clientes, processo interno e aprendizado e crescimento. Na perspectiva financeira seriam considerados os valores criados pela empresa. Assim se estabeleceria uma métrica do sucesso por meio de indicadores financeiros, uma vez que o bom desempenho das empresas privadas está sempre associado a indicadores financeiros (KAPLAN et al., 2004). Em relação à perspectiva de clientes, Kaplan et al. (2004) afirmam que a empresa deve identificar os segmentos de clientes que atende ou que virá a atender, definindo medidas centrais que avaliem as estratégias em relação à satisfação, à retenção, à rentabilidade e à conquista de clientes. No aprendizado e crescimento, o foco é a infraestrutura que a empresa deve ter para que possa crescer de acordo com o pretendido. Isso inclui desde a capacitação dos funcionários, sistemas de gerenciamento e a motivação deles, incentivando-os a seguirem alinhados aos objetivos da organização (KAPLAN et al., 2004).

A partir do entendimento da estratégia e dos objetivos a serem alcançados, ocorre a construção do Mapa Estratégico. Segundo Costa (2006), o mapa estratégico é “o meio pelo qual se operacionaliza a vinculação do planejamento estratégico e o planejamento operacional". Portanto, é um relatório que apresenta os objetivos, metas e ações do Balanced Scorecard, construído para interligar as relações de causa e efeito das quatro perspectivas. Conforme Lunkes et al. (2009), depois de a empresa ter o conhecimento de onde quer chegar e como pretende alcançar os seus objetivos, é necessário elaborar o plano de ação para alcançá-los.

As organizações precisam ter regras e procedimentos bem definidos para que possam crescer. 0 mesmo autor enfatiza ainda que um dos motivos do sucesso de um número considerável de empresas é o 
envolvimento dos gerentes de operações com a administração estratégica. Ressalta, também, que toda organização demanda um sistema de informação e sistemas de controles que forneçam os subsídios necessários para que os processos de tomada de decisão e planejamento estratégico possam ser eficazes.

O desempenho das empresas ficou por muito tempo atrelado a medidas financeiras, norteando estratégias que circulavam ao redor da interação com clientes, de suas capacidades e competências. A implementação de um sistema que tem por objetivo medir o desempenho das ações é de suma importância, pois somente as medidas financeiras não seriam capazes de abarcar informações que reflitam a realidade de um valor econômico futuro (KAPLAN et al., 1997).

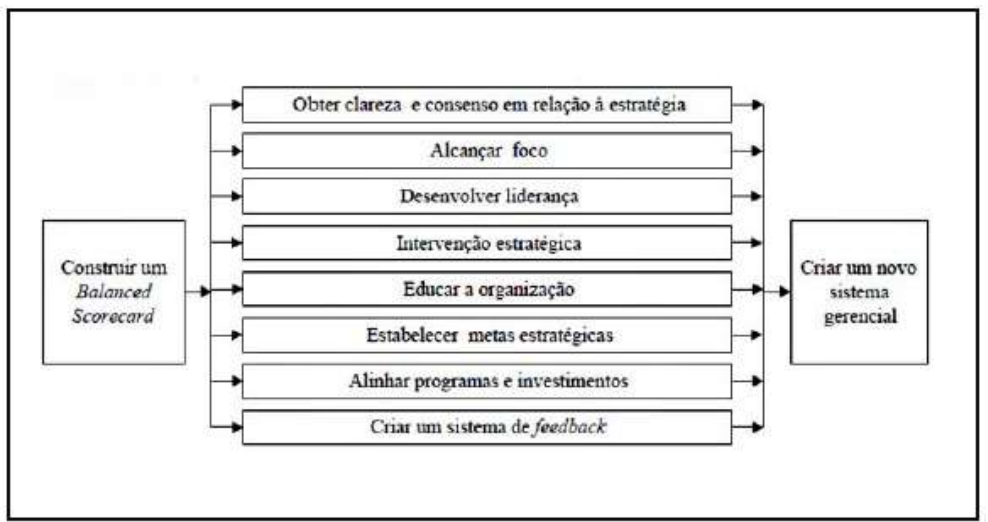

Figura 1: Motivos para uma organização elaborar um Balanced Scorecard. Fonte: Kaplan et al. (1997).

A aplicação do BSC não é a finalidade, mas é um meio de manter a estratégia e os valores de uma empresa ativos para que com isso o sistema gerencial de uma empresa possa ser mantido vivo e alimentado. Kaplan e Norton disponibilizaram uma forma de se fazer isso, mas cada empresa deverá observar as suas peculiaridades e necessidades, como demonstra a figura 2.

A partir desta primeira análise podemos observar que a estrutura definida pela figura 1 e pala figura 2 necessariamente necessita de um controle, de uma verificação cotidiana, não se trata apenas de um checklist. Salientando que para Lunkes (2011), o BSC integra a composição de medidas de desempenho que derivam da estratégia organizacional. Essas medidas direcionam, monitoram e avaliam o aprimoramento dos objetivos estratégicos da organização.

Para a implementação do BSC, faz-se necessário selecionar um arquiteto (ou time de arquitetos) que será responsável pela organização, filosofia e metodologia do projeto, e pelo desenvolvimento do Scorecard, a fim de manter o processo no rumo certo e dentro do prazo. O primeiro passo na elaboração do BSC consiste na revisão, realizada pelos executivos da empresa, da declaração de missão e valores fundamentais da organização (KAPLAN et al., 2001). Depois disso, os executivos devem desenvolver sua visão estratégica e, a partir dela, um conjunto de metas que orientarão os planos de ação.

\section{Estrutura do Balanced Scorecard - Perspectivas e Indicadores}

Um aspecto essencial do Balanced Scorecard é a clara articulação entre medidas de desempenho e objetivos estratégicos. Uma vez que haja um bom entendimento dessas conexões, pode-se definir planos de ação que efetivamente ajudem as organizações a melhorar seu desempenho. De forma resumida, conforme 
Kaplan et al. (2001), Balanced Scorecard contempla objetivos estratégicos e respectivos indicadores em quatro grandes perspectivas.

Os indicadores destacados Balanced Scorecard, adaptado de Kaplan et al. (2001), divididos em financeiro, cliente, processos internos e, o último indicado deles, destacado como aprendizado e crescimento. A partir desta classificação pode-se observar que o Balanced Scorecard contempla as informações financeiras e as análises sobre clientes, processos internos da empresa e destaca a necessidade do aprendizado nas empresas.

\section{Planejamento Estratégico}

Para que a implementação de um modelo de medição de desempenho, como o Balanced Scorecard, possa ser factível, é necessário que a empresa já tenha definido o seu planejamento estratégico. Assim, é preciso descrever "como ela pretende criar valor para seus acionistas, clientes e cidadãos" (KAPLAN et al., 2004). Fernandes et al. (2010) conceituam a estratégia empresarial como sendo "o conjunto dos grandes propósitos, dos objetivos, das metas, das políticas e dos planos para concretizar uma situação futura desejada, considerando as oportunidades oferecidas pelo ambiente e os recursos da organização".

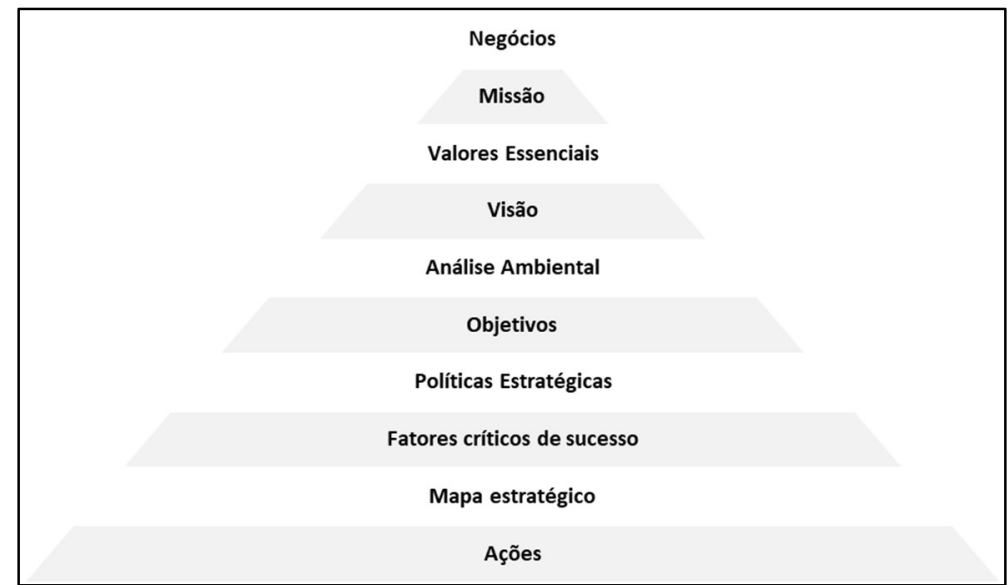

Figura 2: Pirâmide do planejamento estratégico. Fonte: Adaptado de Kaplan et al. (2001; 2004).

O processo, para determinar a estratégia de uma organização, "inicia-se com a imposição dos desejos e aspirações da estrutura do poder, explicados ou mantidos implícitos" (BETHLEM, 2004) em que todos os membros que fazem parte dela são influenciados a seguir os objetivos determinados. Contudo, a estratégia não pode ser considerada um processo gerencial isolado, pois é uma das etapas do processo contínuo que movimenta toda a organização, desde a alta gerência até o chão de fábrica (KAPLAN et al., 2001; 2004). Para uma melhor compreensão do desenvolvimento do planejamento estratégico, a Figura 4 apresenta uma estrutura baseada na literatura sobre o tema, mais fortemente no modelo da visão estratégica arquitetada por Kaplan et al. (2001; 2004), que pode ser considerado eficaz na prática para a descrição da estratégica de uma organização.

Conforme Mussoi et al. (2011), a missão é o propósito de existência da empresa e pode ser considerada o espelho das decisões tomadas pelos gestores para atender os objetivos e estabelecer a direção que orienta a empresa. Já em relação ao entendimento dos valores essenciais da organização, esses são 
bastante estáveis no tempo (KAPLAN et al., 2001; 2004). A importância de se entenderem os valores predominantes da sociedade em que a empresa está inserida, pois eles influenciam de maneira acentuada na escolha dos objetivos dela, pois garante que tenham valores diferentes dos que predominam na sociedade terão dificuldades de agir de acordo com seus valores pessoais.

A fase seguinte do planejamento estratégico é a análise ambiental, que inclui a avaliação de fatores internos e externos que afetam, positiva ou negativamente, a organização. Para Lunkes et al. (2009), na análise do ambiente externo ocorre a identificação de ameaças e oportunidades, levando-se em consideração variáveis macroeconômicas, mercados, clientes, concorrentes, entre outros, e na análise interna ocorre uma avaliação dos pontos fracos e pontos fortes da empresa. Em relação aos objetivos e às metas, esses podem ser entendidos como o estado que se pretende atingir (LUNKES, 2011). Assim, com a definição, descrição e apresentação da missão, valores essenciais, visão e análise ambiental ocorre antes do estudo para a elaboração das estratégias.

\section{Estudos Similares}

Nessa seção foram destacados alguns estudos similares que envolvem a aplicação do Balanced Scorecard nas Microempresas e as dificuldades de implantação dessa ferramenta.

Tabela 1: Estudos anteriores sobre Balanced Scorecard nas microempresas

\begin{tabular}{|c|c|c|c|}
\hline Autores (ano) & Objetivo & Resultado & $\begin{array}{l}\text { Instrumento de pesquisa e } \\
\text { observações }\end{array}$ \\
\hline $\begin{array}{l}\text { Andruchechen } \\
\text { et al. (2013) }\end{array}$ & $\begin{array}{l}\text { Este artigo tem o objetivo de descrever as etapas } \\
\text { para o desenvolvimento do planejamento } \\
\text { estratégico e da implementação do Balanced } \\
\text { Scorecard para atender as necessidades de uma } \\
\text { microempresa que atua no ramo de fabricação de } \\
\text { tintas e revestimentos. }\end{array}$ & $\begin{array}{l}\text { Desenvolveu-se o planejamento } \\
\text { estratégico, seguido pela elaboração do } \\
\text { mapa estratégico e do painel de } \\
\text { desempenho do Balanced Scorecard. } \\
\text { Também, foram definidos os } \\
\text { indicadores-chave de desempenho para } \\
\text { cada um dos objetivos estratégicos, os } \\
\text { responsáveis e as metas a serem } \\
\text { atingidas. }\end{array}$ & $\begin{array}{l}\text { Este estudo é uma pesquisa-ação } \\
\text { com objetivo descritivo, no qual a } \\
\text { definição do portfólio bibliográfico } \\
\text { ocorreu com a utilização da } \\
\text { metodologia Proknow-C, bem como } \\
\text { foram utilizados livros e outros } \\
\text { artigos relacionados ao tema. } \\
\text { Várias reuniões com os } \\
\text { colaboradores da empresa }\end{array}$ \\
\hline $\begin{array}{l}\text { Moreno et al. } \\
(2016)\end{array}$ & $\begin{array}{l}\text { As micro e pequenas empresas (MPEs) brasileiras } \\
\text { enfrentam uma série de problemas relacionados à } \\
\text { gestão deficiente do negócio e que vêm } \\
\text { contribuindo para os elevados índices de } \\
\text { mortalidade observados até o seu quinto ano de } \\
\text { vida. }\end{array}$ & $\begin{array}{l}\text { O presente trabalho apresenta os } \\
\text { resultados de uma pesquisa-ação, onde } \\
\text { buscou-se avaliar a possibilidade de } \\
\text { adequação da metodologia do Balanced } \\
\text { Scorecard ao contexto de uma } \\
\text { microempresa. }\end{array}$ & $\begin{array}{l}\text { O foco dessa avaliação foi a } \\
\text { identificação e compreensão dos } \\
\text { benefícios e das dificuldades } \\
\text { encontradas no processo de } \\
\text { construção do BSC, até o ponto do } \\
\text { desenvolvimento do seu Plano de } \\
\text { Implementação. }\end{array}$ \\
\hline Almeida (2011) & $\begin{array}{l}\text { As estratégias adotadas pelas organizações } \\
\text { empresariais revelam-se fortemente dinâmicas e } \\
\text { de sucesso se forem alvo de constante avaliação, } \\
\text { atribuindo para isso níveis de desempenho, } \\
\text { avaliados por indicadores que apontam qual o } \\
\text { desempenho. }\end{array}$ & $\begin{array}{l}\text { Analisar o interesse na aplicabilidade e } \\
\text { de um modelo Balanced Scorecard para } \\
\text { pequenas e médias empresas, } \\
\text { analisando a relevância que estas dão à } \\
\text { estratégia e aos conceitos relacionados. }\end{array}$ & $\begin{array}{l}\text { Usar como ferramenta de auxílio à } \\
\text { gestão estratégica o Balanced } \\
\text { Scorecard, que permite definir e } \\
\text { avaliar o desempenho de } \\
\text { estratégias. }\end{array}$ \\
\hline $\begin{array}{l}\text { Lavarda et al. } \\
\text { (2011) }\end{array}$ & $\begin{array}{l}\text { O estudo busca investigar o uso do Balanced } \\
\text { Scorecard (BSC) como instrumento que facilita o } \\
\text { processo de planejamento e controle nas } \\
\text { empresas, especificamente no ajuste entre os } \\
\text { objetivos estratégicos e os planos operacionais, } \\
\text { identificando as causas de seu fracasso e/ou } \\
\text { sucesso, por meio da análise de trabalhos } \\
\text { publicados em anais de congressos e revistas } \\
\text { brasileiras. }\end{array}$ & $\begin{array}{l}\text { Entre os resultados, constatou-se que os } \\
\text { principais fatores que facilitam ou } \\
\text { inibem a implantação da ferramenta de } \\
\text { medição de desempenho (BSC) nas } \\
\text { organizações são a cultura } \\
\text { organizacional, a preparação e } \\
\text { motivação dos colaboradores, o } \\
\text { empenho e envolvimento da alta } \\
\text { administração. }\end{array}$ & $\begin{array}{l}\text { Aplicação de ferramentas básicas de } \\
\text { infometria, bibliometria e } \\
\text { cienciometria, com características } \\
\text { descritivas e bibliográficas e uma } \\
\text { abordagem qualitativa dos dados. }\end{array}$ \\
\hline
\end{tabular}

Na tabela anterior, destaca-se o primeiro trabalho de Andruchechen et al. (2013) que descreve sobre as etapas para o desenvolvimento do planejamento estratégico e para a implementação do Balanced 
Scorecard a fim de atender as necessidades de uma microempresa que atua no ramo de fabricação de tintas e revestimentos. Além deste artigo, o trabalho de Moreno et al. (2016) fala sobre os problemas enfrentados pelas as micro e pequenas empresas (MPEs) no Brasil e como instrumentos de controle gerencial podem auxiliar a aumentar a chance de sobrevivência dessas empresas no mercado. Todos os trabalhos destacados descrevem sobre a adequação da metodologia do Balanced Scorecard ao contexto de uma microempresa. 0 foco dessa avaliação foi identificar e compreender os benefícios e as dificuldades encontradas no processo de construção do BSC.

\section{METODOLOGIA}

Nesta seção é descrita a caracterização da pesquisa, os procedimentos metodológicos utilizados para o desenvolvimento do referencial teórico e os instrumentos para a coleta de dados.

\section{Caracterizações da Pesquisa}

A finalidade da caracterização desta pesquisa é demonstrar as etapas para o desenvolvimento do planejamento estratégico e da implementação do Balanced Scorecard em uma empresa que atua com treinamentos e planejamento tributário. Em relação à abordagem do problema, este estudo classifica-se como qualitativo. A interpretação qualitativa dos fatos contribui com o processo de mudança referente à análise de desempenho no decorrer das etapas de desenvolvimento estratégico e de implementação do Balanced Scorecard da empresa (RICHARDSON, 1999).

\section{Procedimentos para o Desenvolvimento do Referencial Teórico}

O portfólio bibliográfico para a construção da fundamentação teórica foi desenvolvido no dia 13 de outubro de 2018 quando foram realizadas pesquisas no banco de dados da ISIS e SCOPUS, disponibilizados na base de periódicos da Coordenação de Aperfeiçoamento de Pessoal de Nível Superior (CAPES), para levantamento de artigos relacionados à área de Ciências Sociais Aplicadas publicados nos últimos 5 anos. Para isso, foram estabelecidos dois eixos de pesquisa, utilizando-se a combinação de palavras relacionadas ao tema como, por exemplo, 'Balanced Scorecard'; 'Performance' e 'BSC'. Desse modo, foram encontrados 4.079 artigos em conformidade aos quesitos até aqui estabelecidos. Inserindo um novo termo 'micro enterprises' a quantidade de artigos disponíveis foi reduzida para 15.

\section{Instrumentos para Coleta de Dados}

Durante a elaboração deste trabalho, além da base teórica anteriormente apresentada, também foram utilizados outros instrumentos para a coleta de informações, que envolveram desenvolvimento da aplicação Balanced Scorecard na microempresa, todos os desenvolvimentos foram articulados com o proprietário da empresa, com isso, concentrou-se as informações na implantação da ferramenta.

Durante a elaboração deste trabalho, além da base teórica anteriormente apresentada, também foram utilizados outros instrumentos para a coleta de informações sobre a aplicação Balanced Scorecard na 
microempresa. Todas essas etapas foram articuladas com o proprietário das microempresas, havendo concentração nas informações sobre a implantação da ferramenta.

\section{RESULTADOS E DISCUSSÃO}

Esta seção é destinada a relatar o desenvolvimento e os resultados da implementação do Balanced Scorecard em uma microempresa que desenvolve a atividade de treinamento e consultoria tributária. Para isso, apresenta-se uma breve descrição da empresa, os passos para o desenvolvimento do planejamento estratégico, a estruturação do mapa estratégico e a definição dos indicadores-chave de desempenho com suas respectivas metas.

\section{Apresentação dos Dados}

As atividades da empresa de treinamento e consultoria tributária em estudo são desenvolvidas pelo empresário de forma individual, sem a colaboração de nenhum colaborador. O profissional atua na região do estado de Santa Cataria há mais de 8 anos, com a atividade de treinamento na parte tributária e contábil.

Além das atividades executadas na empresa em estudo, esse mesmo profissional é docente de graduação em faculdades da região da grande Florianópolis no estado de Santa Catarina, como também é docente em instituições de pós-graduação em nível nacional. Acrescentando às atividades desenvolvidas, trabalha em uma grande empresa da Grande Florianópolis, contratação como celetista cumprindo 40 horas semanais. Essa atuação nas diferentes frentes possibilita visão ampla e estratégica para apontar soluções mais prontas e precisas em relação às necessidades do mercado.

\section{Descrição da Empresa}

A empresa foi constituída no Município de Florianópolis, capital do estado de Santa Catarina. As atividades que a empresa desenvolve estão voltadas ao treinamento empresarial com ênfase na legislação tributária e contábil, com o intuito de manter os profissionais dessa área atualizados frente à grande complexidade da legislação e suas alterações diárias. A atividade da empresa é desenvolvida unicamente pela sócia-fundadora, sem a colaboração de nenhum funcionário neste momento. A profissional atua na região do estado de Santa Cataria há mais de 8 anos, com a atividade de treinamento na parte tributária federal.

Existe uma parceria entre a profissional e uma empresa de consultoria constituída também no mesmo Município, como, também, uma parceria com o Conselho Regional de Contabilidade do Estado de Santa Catarina e os sindicatos da categoria contábil para realização de treinamentos no estado de Santa Catariana. A empresa não possui um planejamento estratégico definido. Portanto, com claro conhecimento quanto às dificuldades enfrentadas para se manter no mercado competitivo, decidiu implementar ferramenta gerencial na empresa, neste caso, o Balanced Scorecard, conforme exemplificado a seguir. 


\section{Implementação do Balanced Scorecard}

A implementação teve início em março de 2018, quando ocorreu o lançamento do programa para implementar o Balanced Scorecard. Este foi o primeiro momento de implantação, após alguns meses de análise as ideias foram sendo amadurecidas e novamente foi feita a análise conceitual para fins de implantação do Balanced Scorecard nessa microempresa individual. Foi fixado como prazo limite dia 31 de outubro de 2018, o que perfez 7 meses para a apresentação desta etapa da sua implementação.

\section{Planejamento Estratégico}

A empresa em estudo, antes desse trabalho, nunca desenvolveu nenhum planejamento estratégico, com isso a aplicação do Balanced Scorecard foi a primeira ferramenta utilizada por ela. Na tabela 2, a definição dos itens iniciais do planejamento estratégico proposto pelo Balanced Scorecard.

Tabela 2: Planejamento estratégico - Atividade da empresa, Missão, Visão e Valores.

\begin{tabular}{l|l}
\hline $\begin{array}{l}\text { Atividade da } \\
\text { Empresa }\end{array}$ & Treinamento profissional na área contábil e tributária. \\
\hline Missão & $\begin{array}{l}\text { Atuar na prestação de serviço de treinamento e desenvolvimento profissional com ênfase na legislação tributária } \\
\text { federal e das normas contábeis, suas atualizações e aplicações, atendendo os profissionais do setor contábil, } \\
\text { tributário, auditoria, advogados e profissionais afins, restrito ao Brasil, com treinamentos presenciais e de forma } \\
\text { online. Proporcionando a difusão das normas contábeis e tributárias e suas alterações. }\end{array}$ \\
\hline Visão & $\begin{array}{l}\text { Ser uma das cinco melhores empresas de consultoria do estado se Santa Catarina, ser lembrada sempre quando } \\
\text { o objetivo da empresa seja minimizar e equalizar a tributação. }\end{array}$ \\
\hline Valores & Desenvolvimento do aprendizado; Ética e transparência; Avaliação dos riscos/benefícios nas decisões. \\
\hline
\end{tabular}

A partir dessas informações, a empresária analisou o ambiente interno da empresa identificando os pontos fortes e fracos. Esses itens estão expostos na tabela 3.

Tabela 3: Planejamento estratégico - Pontos Fortes $X$ Pontos Fracos.

\begin{tabular}{l|ll}
\hline Pontos Fortes & $\checkmark$ & Competência profissional; \\
& $\checkmark$ & Determinação; \\
& $\checkmark$ & Conhecimento da legislação tributária. \\
\hline Pontos Fracos & $\checkmark$ & Concorrência; \\
& $\checkmark$ & Tempo; \\
& $\checkmark$ & Confiança do mercado nos novos profissionais. \\
\hline
\end{tabular}

Posteriormente, foi realizada a análise das condições externas, identificando as oportunidades e as ameaças. Estas informações estão destacadas na tabela 4.

Tabela 4: Planejamento estratégico - Oportunidade X Ameaças.

\begin{tabular}{l|ll}
\hline Oportunidades & $\checkmark$ & Legislação Tributária extremamente complexa; \\
& $\checkmark$ & Falta de conhecimento dos profissionais envolvidos; \\
& $\checkmark$ & Dificuldade na interpretação da Legislação. \\
\hline Ameaças & $\checkmark$ & Falta de pessoas competentes para trabalhar; \\
& $\checkmark$ & Tempo; \\
& $\checkmark$ & Concorrência desleal por valores irrisórios. \\
\hline
\end{tabular}

Analisando as informações levantadas por meio das tabelas 3 e 4, pode-se iniciar a estruturação do mapa estratégico da empresa em discussão. Segundo Kaplan et al. (2000), o mapa estratégico representa a descrição da estratégica da entidade por meio de uma arquitetura genética, além disso, conforme definido na Figura 3 deste trabalho, os indicadores do Balanced Scorecard contemplam objetivos estratégicos e 
respectivos indicadores em quatro grandes perspectivas: (1) financeira, (2) clientes, (3) processos internos e (4) aprendizado e crescimento. Estas ligações e estratégica estão demonstradas na Figura 3.

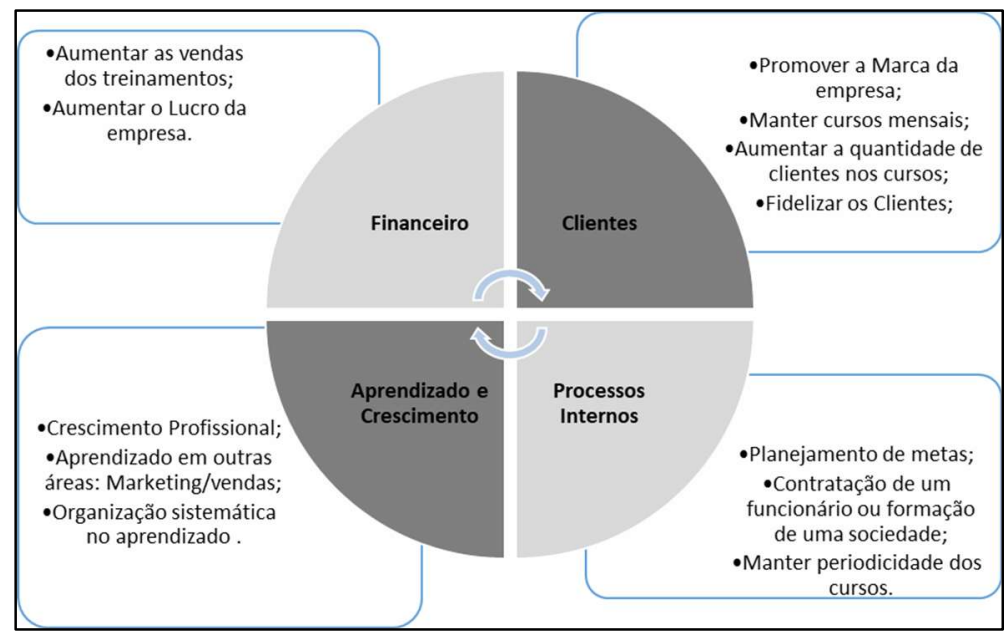

Figura 3: Quadro Estratégico.

$\mathrm{Na}$ figura 3, destacam-se as sugestões encontradas para fins de implantação estratégica de crescimento e desenvolvimento da empresa, diante dessa análise, destacaram-se 12(doze) objetivos que estão divididos nas quatro perspectivas do Balanced Scorecard. Conforme destacado por Kaplan et al. (2004), cada empresa deve construir o mapa estratégico determinando os objetivos conforme as suas necessidades específicas. Além disso, esses autores sugerem vinte ou trinta indicadores para o Balanced Scorecard, entretanto, o estudo destaca 12 (doze) indicadores divididos nas quatro divisões, esse número mais reduzido destaca-se pelo fato de tratar-se de uma microempresa em início da sua atividade.

Na perspectiva do aprendizado e do crescimento destacam-se a necessidade de desenvolvimento profissional, de aprendizado constante e de aplicação dele em outras áreas, pois, por exemplo, cada vez mais a interação com a área de publicidade, de processo de vendas e de fidelização dos clientes é muito necessária.

No seguinte item destaca-se a questão dos processos internos. Considera-se um grande passo para a questão do crescimento, considerando-se que exista um potencial de crescimento, a ampliação do quadro de recursos humanos, seja pela contratação de novos trabalhadores e/ou pela admissão de um novo sócio, entretanto as duas possibilidades devem ser analisadas, pois se trata de um segmento que envolve um material intelectual aplicado e esta estratégia precisa ser muito bem planejada com metas de periodicidade fixa como, por exemplo, disponibilizar treinamentos mensais.

Percorrendo a Figura 3, o item clientes é o principal a ser analisado, pois usufruem e sustentam o mecanismo de qualquer empresa. Para fins estratégicos, relativos a este item, inclui-se a questão da promoção da marca da empresa e o aumento da quantidade de clientes nos cursos por meio de fidelização.

Por fim, temos a situação financeira, cujo indicador por excelência é o aumento nas vendas dos treinamentos, o que por consequência aumenta o lucro da empresa. Desta forma, definidos os objetivos dentro de cada uma das perspectivas, a próxima etapa tem a finalidade de incorporar indicadores, responsáveis e metas. É a etapa que apresenta os objetivos e os indicadores de cada item anteriormente apresentados. 


\section{Definição dos Indicadores de Desempenho e Meta}

A escolha dos indicadores de desempenho pelo empresário foi destacada no item anterior, a partir desta construção é que eles têm origem e serão aplicados na empresa. Após a definição deles em relação aos que melhor atendem aos objetivos levantados durante o planejamento estratégico deste modelo de gestão, eles são colocados no painel de desempenho da empresa, conforme definido na tabela 5, que está dividida em 5 colunas e 12 linhas, de acordo com os indicadores destacados na Figura 3, divididos em conformidade com o estudo do Balanced Scorecard nos quatro itens de desempenho.

Na segunda coluna, podem ser observados os objetivos estratégicos, ao lado, na coluna 3, observamse os indicadores de desempenho para alinharem-se aos objetivos, na sequência segue-se a periodicidade de cada indicador e, por fim, a meta estabelecida. Lembrando que todas as fontes de indicadores estão restritas ao titular da empresa. Na análise da tabela 5 poderão ser observados os indicadores construídos com a finalidade de crescimento estruturado da microempresa.

Tabela 5: Indicadores de Desempenho e Meta.

\begin{tabular}{|c|c|c|c|c|c|c|c|c|}
\hline & \multirow{2}{*}{$\begin{array}{l}\text { Objetivos } \\
\text { estratégicos }\end{array}$} & \multirow{2}{*}{ Indicadores de desempenho } & \multicolumn{2}{|c|}{ Referência } & \multirow{2}{*}{ Situação Atual } & \multirow{2}{*}{ Meta } & \multirow{2}{*}{ Periodicidade } & \multirow{2}{*}{ Iniciativas } \\
\hline & & & Superior & Inferior & & & & \\
\hline \multirow{3}{*}{ 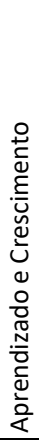 } & $\begin{array}{l}\text { Crescimento } \\
\text { Profissional }\end{array}$ & $\begin{array}{l}\text { Aperfeiçoamento do titular da } \\
\text { empresa }\end{array}$ & & $x$ & $\begin{array}{l}\text { Em } \\
\text { andamento, } \\
\text { mas uma } \\
\text { constância. } \\
\end{array}$ & $\begin{array}{l}\text { Maior } \\
\text { quantidade } \\
\text { possível }\end{array}$ & Semanal & Leituras e estudos \\
\hline & $\begin{array}{l}\text { Aprendizado em } \\
\text { outras áreas: } \\
\text { Marketing; } \\
\text { vendas. }\end{array}$ & $\begin{array}{l}\text { Contratação de Cursos } \\
\text { Contratação de terceiros para } \\
\text { divulgação }\end{array}$ & $x$ & & $\begin{array}{l}\text { Em } \\
\text { andamento, } \\
\text { mas uma } \\
\text { constância }\end{array}$ & $\begin{array}{l}\text { Maior } \\
\text { quantidade } \\
\text { possível }\end{array}$ & Trimestral & $\begin{array}{l}\text { Pesquisa de mercado } \\
\text { dos profissionais } \\
\text { disponíveis }\end{array}$ \\
\hline & $\begin{array}{l}\text { Organização } \\
\text { sistemática no } \\
\text { aprendizado }\end{array}$ & Organização & & $x$ & $\begin{array}{l}\text { Em } \\
\text { andamento, } \\
\text { mas uma } \\
\text { constância }\end{array}$ & $\begin{array}{l}\text { Maior } \\
\text { quantidade } \\
\text { possível }\end{array}$ & Semanal & $\begin{array}{l}\text { Desenvolver um } \\
\text { roteiro }\end{array}$ \\
\hline \multirow{3}{*}{ 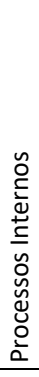 } & $\begin{array}{l}\text { Planejamento de } \\
\text { metas curto e } \\
\text { longo prazo }\end{array}$ & Organização & & $x$ & $\begin{array}{l}\text { Sem } \\
\text { organização }\end{array}$ & $\begin{array}{l}\text { Observar o } \\
\text { cumprimento de } \\
\text { forma Semestral }\end{array}$ & Semestral & $\begin{array}{l}\text { Desenvolver um } \\
\text { roteiro de ações de } \\
\text { curto e longo prazo }\end{array}$ \\
\hline & \begin{tabular}{|l|} 
Contratação de \\
um funcionário ou \\
formação de uma \\
sociedade
\end{tabular} & $\begin{array}{l}\text { Planejamento de controle/ } \\
\text { Avaliação do crescimento e da } \\
\text { demanda }\end{array}$ & $x$ & & Sem Controle & Em Análise & 2 Anos & $\begin{array}{l}\text { Desenvolver um } \\
\text { roteiro de crescimento } \\
\text { a longo prazo }\end{array}$ \\
\hline & \begin{tabular}{|l|} 
Manter \\
periodicidade dos \\
cursos
\end{tabular} & Faturamento/Organização & & $x$ & Sem Controle & Mensal & Mensal & $\begin{array}{l}\text { Manter os programas } \\
\text { sempre atualizados }\end{array}$ \\
\hline \multirow[b]{4}{*}{ 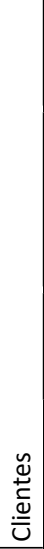 } & $\begin{array}{l}\text { Promover a } \\
\text { Marca da } \\
\text { empresa }\end{array}$ & $\begin{array}{l}\text { Encaminhar } \\
\text { propagandas/Promover a } \\
\text { Marca }\end{array}$ & & $x$ & $\begin{array}{l}\text { A marca não é } \\
\text { divulgada }\end{array}$ & $\begin{array}{l}\text { Maior } \\
\text { quantidade } \\
\text { possível }\end{array}$ & Mensal & $\begin{array}{l}\text { Desenvolver } \\
\text { programas de } \\
\text { relacionamento }\end{array}$ \\
\hline & $\begin{array}{l}\text { Aumentar a } \\
\text { quantidade } \\
\text { Clientes }\end{array}$ & $\begin{array}{l}\text { Encaminhar } \\
\text { propagandas/Promover a } \\
\text { Marca }\end{array}$ & & $x$ & Sem Controle & $\begin{array}{l}\text { Manter } \\
\text { controle; Maior } \\
\text { quantidade } \\
\text { possível }\end{array}$ & Mensal & $\begin{array}{l}\text { Desenvolver } \\
\text { programas de } \\
\text { relacionamento }\end{array}$ \\
\hline & $\begin{array}{l}\text { Manter cursos } \\
\text { disponíveis } \\
\text { mensais }\end{array}$ & $\begin{array}{l}\text { Planejamento/controle do } \\
\text { tempo disponível }\end{array}$ & & $x$ & Sem Controle & $\begin{array}{l}\text { Maior } \\
\text { quantidade } \\
\text { possível }\end{array}$ & Mensal & $\begin{array}{l}\text { Manter os programas } \\
\text { sempre atualizados }\end{array}$ \\
\hline & $\begin{array}{l}\text { Fidelizar os } \\
\text { clientes }\end{array}$ & Encaminhar propagandas & & $x$ & Sem Controle & $\begin{array}{l}\text { Maior } \\
\text { quantidade } \\
\text { possível }\end{array}$ & Mensal & $\begin{array}{l}\text { Realizar pesquisas } \\
\text { para identifica o nível } \\
\text { de satisfação dos } \\
\text { participantes }\end{array}$ \\
\hline
\end{tabular}




\begin{tabular}{|c|c|c|c|c|c|c|c|}
\hline & $\begin{array}{l}\text { Aumentar as } \\
\text { vendas dos } \\
\text { treinamentos }\end{array}$ & Variação do faturamento & $x$ & Sem Controle & Confidencial & Trimestral & $\begin{array}{l}\text { Desenvolver ações } \\
\text { estratégicas de } \\
\text { divulgação que } \\
\text { possam alcançar maior } \\
\text { quantidade de } \\
\text { Clientes }\end{array}$ \\
\hline 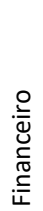 & $\begin{array}{l}\text { Aumentar o lucro } \\
\text { da empresa }\end{array}$ & $\begin{array}{l}\text { Rentabilidade X1/ } \\
\text { Rentabilidade X0 }\end{array}$ & $x$ & Sem Controle & Confidencial & Trimestral & $\begin{array}{l}\text { Desenvolver ações } \\
\text { estratégicas de } \\
\text { divulgação que } \\
\text { possam alcançar maior } \\
\text { quantidade de } \\
\text { Clientes }\end{array}$ \\
\hline
\end{tabular}

Lembrando que o BSC se trata de uma ferramenta, e não de uma finalidade, diante dessa situação, observa-se uma estrutura considerável de planejamento para o desenvolvimento e crescimento estratégico dessa microempresa. Além disso, as dificuldades de definição e de metas enquadradas para o desenvolvimento desses indicadores demonstram como um empresário pode estar despreparado para o desenvolvimento de uma empresa, pois somente conhecer bem o mercado não faz com que a empresa tenha bons resultados, já que o desenvolvimento técnico da empresa é parte do desenvolvimento dela.

\section{CONCLUSÕES}

A aplicação do Balanced Scorecard (BSC) tem o objetivo estratégico de posicionar no mercado uma empresa como uma ferramenta auxiliar ao planejamento. Ao longo dos anos, o BSC evoluiu para uma ferramenta de gestão estratégica e por isso passou a receber ainda mais atenção dos profissionais e acadêmicos.

Em um contexto competitivo e uma economia frágil as empresas brasileiras passam por várias dificuldades para se manter no mercado, vários índices de mortalidade são estudados e discutidos e as microempresas não estão fora deste cenário, este estudo tem como proposta a aplicação de uma ferramenta auxiliar de gestão estratégica: Balanced Scorecard em uma microempresa de treinamento no setor tributário que permite, inicialmente, definir e avaliar o desempenho de estratégias em quatro vertentes, a financeira, os clientes, os processos internos da organização e o nível de conhecimento ou aprendizagem organizacional.

A escolha do BSC para este estudo é porque utiliza indicadores de desempenho para informar os motivos de sucesso atual e futuro da empresa a fim de alcançar as metas traçadas. Esse destaque para o Balanced Scorecard está centrado no conceito das quatro perspectivas: (1) a Perspectiva Financeira que identifica como a empresa quer ser vista por seus acionistas; (2) a Perspectiva do Cliente que identifica como a empresa quer ser vista por seus clientes; (3) a Perspectiva Interna que descreve como executar as estratégias da empresa e (4) a Perspectiva de Aprendizado que permite identificar e trabalhar nas eventuais defasagens de capital humano e de informação.

$\mathrm{Na}$ atualidade, principalmente as empresas de grande porte, realizam avaliações de desempenho, mais especificamente com a metodologia do Balanced Scorecard. Porém, este método de avaliação de desempenho também pode ser aplicado em pequenas empresas, como pode ser visto neste artigo. Para a implementação do Balanced Scorecard da empresa em estudo, foi necessário, antes de tudo, montar o planejamento estratégico da empresa: Negócio, Missão, Visão e Valores da empresa. Esse planejamento 
estratégico foi tomado como base para a construção do mapa estratégico e posteriormente para a construção do painel do Balanced Scorecard.

O painel de desempenho foi desenvolvido de acordo com a realidade da empresa estudada, onde foram encontrados 12 objetivos estratégicos entre as 4 Perspectivas do Balanced Scorecard: aumentar as vendas dos treinamentos; aumentar o lucro da empresa; promover a marca da empresa; manter cursos mensais; aumentar a quantidade de clientes nos cursos; fidelizar os clientes; planejaras metas; contratar funcionário ou formar sociedade; manter periodicidade dos cursos; fomentar o crescimento profissional; fomentar o aprendizado em outras áreas como marketing/vendas; organizar sistematicamente o aprendizado. Para cada um foi designado indicador de desempenho que direciona o objetivo traçado pela empresa com o objetivo de crescimento e desenvolvimento estratégico.

Observa-se que a implantação dos indicadores do Balanced Scorecard em uma microempresa é capaz de fornecer informações para apoiar as decisões dos gestores e principalmente de ser uma possibilidade de nortear o futuro da empresa para que essa tenha objetivo traçado a longo prazo alcançando, assim, o objetivo deste trabalho. Entretanto, o porte da empresa neste estudo foi um limitador, além de se tratar de uma empresa em início de atividade, com isso, não há um histórico a ser analisado, apenas uma estrutura inicial com objetivos de desenvolvimento e crescimento futuro.

\section{REFERÊNCIAS}

ANDRUCHECHEN, J. R.; BELI, A. P.; ALBERTON, L.; PETRI, S. M.. Proposta de implementação do planejamento estratégico e balanced scorecard: um estudo em uma microempresa de manufatura. Revista de Estudos Contábeis, Londrina, v.4, n.7, p.57-76, 2013.

COSTA, A. P. P.. Balanced Scorecard: conceitos e guias de implementação. São Paulo: Atlas, 2006.

KAPLAN, R. S.; NORTON, D. P.. Kaplan e Norton na Prática. 5 ed. Rio de Janeiro: Elsevier, 2004.

KAPLAN, R. S.; NORTON, D. P.. A estratégia em ação: Balanced Scorecard. 24 ed. Rio de Janeiro: Elsevier, 1997.

KAPLAN, R. S.; NORTON, D. P.. Organização orientada para a estratégia: Como as empresas que adotam o balanced scorecard prosperam no novo ambiente dos negócios. 16 ed. Rio de Janeiro: Elsevier, 2001

KAPLAN, R. S.; NORTON, D. P.. Mapa estratégico: Balanced Scorecard: convertendo ativos intangíveis em resultados tangíveis. 9 ed. Rio de Janeiro: Elsevier, 2004.
LUNKES, R. J.. Manual de orçamento. 2 ed. São Paulo: Atlas, 2011.

LUNKES, R. J.; SCHNORRENBERGER, D.. Controladoria: na coordenação dos sistemas de gestão. São Paulo: Atlas, 2009.

MOORAJ, S.; OYON, D.; HOSTETTLER, D.. The balanced scorecard: a necessary good or an unnecessary evil?. European Management Journal, v.17, n.5, p.481-491, 1999.

MUSSOI, A.; LUNKES, R. J.; SILVA, R. V.. Missão institucional: uma análise da efetividade e dos principais elementos presentes nas missões de empresas brasileiras de capital aberto. Rege, São Paulo, v.18, n.3, p.361-384, 2011.

NEELY, A.. The evolution of performance measurement research. Developments in the last decade and a research agenda for the next. International Journal of Operations \& Production Management, v.25, n.12, p.1264-1277, 2005.

RICHARDSON, J. R.. Pesquisa Social: Métodos e Técnicas. 3 ed. São Paulo: Atlas, 1999.

A CBPC - Companhia Brasileira de Produção Científica (CNPJ: 11.221.422/0001-03) detém os direitos materiais desta publicação. Os direitos referem-se à publicação do trabalho em qualquer parte do mundo, incluindo os direitos às renovações, expansões e disseminações da contribuição, bem como outros direitos subsidiários. Todos os trabalhos publicados eletronicamente poderão posteriormente ser publicados em coletâneas impressas sob coordenação da Sustenere Publishing, da Companhia Brasileira de Produção Científica e seus parceiros autorizados. Os (as) autores (as) preservam os direitos autorais, mas não têm permissão para a publicação da contribuição em outro meio, impresso ou digital, em português ou em tradução. 